\title{
The Role of Epilepsy and Epileptiform EEGs in Autism Spectrum Disorders
}

\author{
SARAH J. SPENCE AND MARK T. SCHNEIDER
}

Pediatrics and Developmental Neuroscience Branch, National Institute of Mental Health, NIH, Bethesda, Maryland 20892-1255

\begin{abstract}
Autism is a neurodevelopmental disorder of unknown etiology characterized by social and communication deficits and the presence of restricted interests/repetitive behaviors. Higher rates of epilepsy have long been reported, but prevalence estimates vary from as little as $5 \%$ to as much as $46 \%$. This variation is probably the result of sample characteristics that increase epilepsy risk such as sample ascertainment, lower intelligence quotient (IQ), the inclusion of patients with nonidiopathic autism, age, and gender. However, critical review of the literature reveals that the rate in idiopathic cases with normal IQ is still significantly above the population risk suggesting that autism itself is associated with an increased risk of epilepsy. Recently, there has been interest in the occurrence of epileptiform electroencephalograms (EEGs) even in the absence of epilepsy. Rates as high as $60 \%$ have been reported and some investigators propose that these abnormalities may play a causal role in the autism phenotype. Although this phenomenon is still not well understood and risk factors have yet to be determined, the treatment implications are increasingly important. We review the recent literature to elucidate possible risk factors for both epilepsy and epileptiform EEGs. We then review existing data and discuss controversies surrounding treatment of EEG abnormalities. (Pediatr Res 65: 599-606, 2009)
\end{abstract}

A utism and related autism spectrum disorders (ASD) are lifelong, often severely impairing neurodevelopmental syndromes involving deficits in social relatedness, language, and behavior. Reports of increasing prevalence, the lack of well-controlled studies on treatment efficacy, and the immense costs of education and care for these patients all combine to make autism a public health crisis. However, despite a large body of careful pharmacological, pathologic, electrophysiological, and imaging investigations, the etiology of autism remains unclear. Known medical conditions account for only a fraction (5-20\%) of autism (1-3). Comorbidity with other neurologic disorders, demonstrated widespread neuropathological changes, and an emerging literature of structural and functional neuroimaging differences in autism all herald an underlying central nervous system (CNS) abnormality.

One of the best-known associations with CNS dysfunction is the high risk of epilepsy. This has been known since the first cases of autism (4) and is commonly reported to

Received October 7, 2008; accepted November 23, 2008.

Correspondence: Sarah J. Spence, M.D., Ph.D., 10 Center Dr., MSC 1255, Building

10, Rm 4N208, Bethesda, MD 20892-1255; e-mail: spences2@mail.nih.gov

Supported by the intramural research program of the NIMH, XFF 80100.

This work was written as part of the authors' official duties as Government employees. The article is freely available for publication without a copyright notice, and there are no restrictions on its use, now or subsequently. The views expressed in this chapter do not necessarily represent the views of the NIMH, NIH, HHS, or the United States Government. occur in $1 / 3$ of individuals with ASD. However, the exact prevalence remains unknown and the literature presents a wide range of estimates from 5 (5) to $46 \%$ (6). ASD is also increased in epilepsy populations, with as high as $32 \%$ (7) meeting diagnostic criteria.

There is no primary seizure type or syndrome associated with autism. Complex partial (with or without secondarily generalized seizures), absence, and generalized tonic-clonic have all been reported $(8-12)$. The diagnosis of seizure activity in autistic individuals is made more difficult because the behavioral abnormalities associated with complex partial and/or absence seizures (e.g., staring and nonresponsiveness with or without repetitive motor behaviors) can all be attributed to the autism. Recently, there have also been reports of high rates of epileptiform electroencephalogram (EEGs) in children with autism without a history of seizures or epilepsy $(13,14)$.

The increased prevalence of epilepsy and/or epileptiform EEG abnormalities in individuals with ASD may be an important clue to an underlying neurologic abnormality, at least for a subset of autism patients. However, there are no definitive data to help predict which children will develop epilepsy and/or EEG abnormalities and to what degree cognition, behavior, and other phenotypic characteristics are affected. Fundamental questions regarding the relationship among the occurrence of epilepsy, and the cognitive, language, and behavioral deficits seen in autism are still unanswered: is this just an epiphenomenon of the underlying neural dysfunction in autism, or is there a causal relationship (15)?

A critical review of the literature points to several characteristics that seem to be associated with the presence of epilepsy in ASD including: intelligence quotient (IQ), additional neurogenetic disorders, age, developmental regression, and gender. This article evaluates the association of these features with both clinical epilepsy and epileptiform EEG abnormalities in individuals with autism in an attempt to identify risk factors. We also review treatment strategies and discuss emerging ideas in this area.

Abbreviations: AED, Anti-epileptic Drug; ASD, Autism Spectrum Disorder; BECTS, Benign Epilepsy with Centrotemporal Spikes; CNS, Central Nervous System; EEG, Electroencephalogram; IQ, Intelligence Quotient; LKS, Landau Kleffner Syndrome; TSC, Tuberous Sclerosis Complex 


\section{RATES OF EPILEPSY IN AUTISTIC SPECTRUM DISORDERS}

\section{Variability and Sample Characteristics}

Table 1 provides rates from studies published since 2000 showing the wide range of estimates. Sample variability is most likely responsible for these disparities. Sample ascertainment strategies and inclusion of individuals with different cognitive levels, ages, and comorbid medical conditions contribute to rate differences.

Ascertainment. Referral or ascertainment bias may be the most important confounding factor. Clinic-based samples report higher rates, as patients with epilepsy are overrepresented in these settings (6). Population-based studies avoid this bias and provide the best estimate of true prevalence of epilepsy in autism, but even those rates have been variable. A review (16) of nine population based studies reported epilepsy prevalence with a median of $17 \%$ and a range of 5-26\%. Another long-term follow-up study of a populationbased sample reported a substantially higher lifetime epilepsy prevalence of $38 \%$ (10). Clearly, other factors are at play in producing these variable rates.

Intellectual disability. It has been posited that the presence of intellectual disability drives the association between epilepsy and ASD. Certainly, a high percentage of children on the autism spectrum have comorbid intellectual disability (16), and intellectual disability is an independent risk factor for developing epilepsy (17).

Most studies have reported an association between low IQ and increased epilepsy in autism $(8,9,11,18-21)$. A metaanalysis of 10 studies demonstrated a higher pooled epilepsy prevalence rate in individuals with $(21.5 \%) v s$. without $(8 \%)$ intellectual disability (22). Also, patients with both intellectual disability and active epilepsy have high rates of autism (8).
However, it should be noted that other studies show no statistically significant association between epilepsy and IQ in autism $(23,24)$, and the rate of epilepsy is still much above the general population risk even among individuals with normal IQ $(22,25)$. Thus, although intellectual disability increases the risk, it seems that autism itself is associated with higher epilepsy rates.

Idiopathic vs. complex or syndromic autism. There is a small subset of ASD cases with known comorbid medical conditions believed to be causally related; and these often have high rates of epilepsy themselves (tuberous sclerosis complex (TSC), Fragile X syndrome, 15q duplication syndrome, among others) $(2,26,27)$. These cases are referred to as nonidiopathic or syndromic, and their inclusion in autism samples inflates epilepsy prevalence estimates.

Studies have shown higher rates of epilepsy in nonidiopathic groups compared with idiopathic groups $(2,18)$ and studies limiting the sample to purely idiopathic autism reported lower rates of epilepsy $(13-17 \%(11,28))$. Again, these rates in idiopathic ASD are still substantially above the general population risk of epilepsy (1 to $2 \%$ ) suggesting that autism itself is associated with increased epilepsy risk.

Age. There are two peaks in the age of onset of epilepsy in ASD (16,19): first in early childhood and second (perhaps higher) in adolescence $(11,29)$. Thus, some of the variability in reported rates is simply a function of the age of the sample with some of the highest reported in studies including adolescents and young adults $(6,10,30)$.

Developmental regression. A noticeable loss of skills, or developmental regression, occurs in up to $1 / 3$ of children with autism (31). The period of regression usually occurs between 18 and 24 mo of age and can occur in those who were developing normally or in those with preexisting developmental delays. Researchers have been interested in the phenomenon and its relationship to epilepsy because of the idea that an

Table 1. Summary of studies published since 2000 examining the prevalence of epilepsy in ASD populations including sample characteristics (sample size, age, ascertainment methods, diagnoses, whether the sample includes nonidiopathic autism)

\begin{tabular}{|c|c|c|c|c|c|c|}
\hline $\begin{array}{l}\text { Sample } \\
\text { size }\end{array}$ & Age & Ascertainment & Diagnosis & $\begin{array}{l}\text { Sample includes } \\
\text { nonidiopathic }\end{array}$ & $\begin{array}{c}\text { Epilepsy rate in total } \\
\text { sample and sample subgroups }\end{array}$ & Reference \\
\hline 2112 & $\mathrm{n} / \mathrm{a}$ & Mixed & Autism, PDD & Yes & $\begin{array}{l}\text { With intellectual disability, } 21.4 \% \text {; } \\
\text { without intellectual disability, } \\
8 \% \text {; male, } 18.5 \% \text {; female, } 34.5 \%\end{array}$ & 22 \\
\hline 46 & Mean, 7.8 y & Clinic based & Autism, PDD & No & Total sample, $13 \%$ & 28 \\
\hline 108 & Mean, 25.5 y & Population based & Autistic or "autistic like" & Yes & Total sample, $38 \%$ & 10 \\
\hline 56 & Range, $1-14$ y & Clinic based & Autism, PDD, Asperger's & Yes & $\begin{array}{l}\text { Total sample, } 28 \% \text {; autism, } 40.0 \% \text {; } \\
\text { PDD, } 11.1 \%\end{array}$ & 38 \\
\hline 104 & Range, 30 mo- 8 y & Clinic based & Autism or ASD & Yes & Total sample, $19.4 \%$ & 33 \\
\hline 60 & $\begin{array}{l}\text { Mean, } 17.6 \mathrm{y} \text {; range, } \\
12-30 \mathrm{y}\end{array}$ & Clinic based & Autism & No & $\begin{array}{l}\text { Total sample, } 38.3 \% \text { (includes } \\
\text { febrile seizures) }\end{array}$ & 30 \\
\hline 130 & Range, $18-35$ y & Clinic based & Autism, PDD & No & $\begin{array}{l}\text { Total sample, } 17 \% \text { ( } 25 \% \text { when } 1 \\
\quad \text { seizure included) }\end{array}$ & 11 \\
\hline 77 & Mean, 9.1 y & Clinic based & $\begin{array}{l}\text { Autism, PDD, Asperger's, } \\
\text { CDD }\end{array}$ & No & Total sample, $22.1 \%$ & 21 \\
\hline 59 & Range, $0.5-21$ y & Clinic based & Autism & Yes & Total sample, $46 \%$ & 6 \\
\hline 32 & Mean, 5 y & Clinic based & Autism & No & Total sample, $36 \%$ & 14 \\
\hline 77 & Mean, 17 y & Clinic based & Autism, PDD & Yes & Autism, $20.8 \%$; PDD, $35.1 \%$ & 12 \\
\hline 72 & $\begin{array}{l}\text { Mean, } 9 \text { y; range, } \\
4-21 \text { y }\end{array}$ & Clinic based & Autism & Yes & $7 \%$, Idiopathic; $55 \%$, nonidiopathic & 18 \\
\hline 233 & Range, $1-56$ y & Clinic based & Autism, Asperger's & Yes & 17\%, "essential;" 39\%, "complex" & 2 \\
\hline
\end{tabular}

Rates are presented for total samples and special populations within a given sample such as those with and without intellectual disability or gender or specific diagnoses. 
epileptic encephalopathy may play a role in the etiology of autism. However, results are inconsistent.

Several studies report statistically significant associations between the presence of regression and an increase in epilepsy $(21,32,33)$. In contrast, other studies show no increases or associations between epilepsy and regression $(11,20,28,31)$. It is possible that other sample variables could be confounding factors; however, the relationship between regression and epilepsy in autism remains unclear.

Gender. Literature suggests an increased risk of epilepsy in females as opposed to males $(6,10,24)$. A recent meta-analysis found the male to female ratio in autism with epilepsy was close to $2: 1$ vs. 3.5:1 in autism without epilepsy and a higher pooled prevalence of epilepsy in females than males (34.5 vs. $18.5 \%$ ) (22). In contrast, another study of idiopathic autism reported no significant differences in gender ratios (11). It is unclear whether this is an effect of female gender per se or whether more females have other risk factors such as lower IQ and nonidiopathic autism.

Summary. As reviewed, there is an increased risk of epilepsy in ASD and many factors may further increase this risk. However, these factors may not exist independently in a given patient. For example, an individual may have a lower IQ because of a comorbid neurogenetic syndrome that presents with early onset epilepsy. Unfortunately, existing studies have rarely had the sample sizes and phenotypic detail to determine which of these factors is most important in explaining the patient's increased epilepsy risk.

Future research that teases apart these features is imperative to accurately predict the individuals with ASD who are at increased risk of developing epilepsy. Furthermore, almost nothing is known about the relationship of epilepsy to the core features of autism: is the social domain more or less affected by epilepsy than language or repetitive behaviors? From a practical standpoint clinicians need to be aware of these risk factors to provide appropriate work-up and counseling to families. Neurogenetic disorders occur more frequently in the ASD patients with epilepsy and intellectual disability, often warranting specific diagnostic testing.

\section{SUBCLINICAL EPILEPTIFORM ABNORMALITIES IN THE ABSENCE OF EPILEPSY IN ASD}

There are many reports of background or interictal EEG changes in individuals with autism. It is important to note that these abnormalities may occur in individuals without seizures and their presence should not be considered evidence of epilepsy. Rather, these EEG changes are considered to be signs of cerebral dysfunction. Both nonspecific changes, such as slowing or asymmetry, and epileptiform discharges, consisting of spikes or sharp wave discharges, sharp slow waves, generalized spike-wave, and generalized polyspikes are seen. Epileptiform discharges are common among patients with active epilepsy, but are reportedly rare (1 to 4\%) in healthy children $(34,35)$. One intriguing finding in ASD is the high rates of these abnormalities, even in the absence of epilepsy. This raises questions about whether these discharges could be considered a biomarker of cortical dysfunction in this popu- lation, and whether these discharges have a causal association with any of the autism phenotypes.

Much like rates of epilepsy, reported rates of epileptiform abnormalities are quite variable. This may be due to sample characteristics and/or the methodological variability in collecting and interpreting EEGs. Many studies report an overall EEG abnormality rate by combining individuals with and without epilepsy. Referral bias may also play a major role, as there are no population-based studies of rates of epileptiform discharges among individuals with ASD. Most reports are retrospective reviews of large clinic samples meaning that the clinical practice of the individual investigator will influence the data. Differences in EEG type (routine office studies vs. prolonged recording, whether sleep is captured) have also been shown to affect rates.

\section{Rates of Epileptiform Discharges}

Until recently, reported rates of interictal epileptiform discharges varied from 6 to $30 \%$ of ASD patients $(19,20,29,31)$. Recently, even higher rates of isolated epileptiform EEGs have been reported (see Table 2).

Several studies have reported epileptiform abnormality rates of approximately $30 \%$ in ASD patients without clinical seizures $(21,36,37)$. One study of children referred for video EEG monitoring to evaluate possible seizures found interictal epileptiform abnormalities in 59\% (14). Although some of the patients had a history of seizures, there were no seizures captured on monitoring so that these were isolated epileptiform discharges. Interestingly, the history of epilepsy did not predict the likelihood of abnormalities in this cohort. A retrospective review of almost 900 children with ASD who had no known history of epilepsy, found $61 \%$ with epileptiform EEG activity in sleep (13). These latter studies are important because they show that this pattern could represent a common objective physiologic finding in ASD, something that is difficult to find in this heterogeneous behaviorally defined condition.

However, lower rates (4-22\%) were also reported in recent studies $(11,12,28,38)$. Some of these differences may be explained by methodological and sample differences. Some samples were purely idiopathic $(11,30)$. Others used routine EEGs rather than prolonged studies which could lessen sensitivity $(11,12)$. Clearly, large prospective trials in unselected populations of autism are needed to determine the true rate of interictal epileptiform discharges. Data could help determine other risk factors and to delineate the role (if any) of these discharges in the autism phenotype.

\section{Other Variables Affecting Rates of Isolated Epileptiform Discharges}

Regression. As with epilepsy, the association between the occurrence of regression and epileptiform EEG abnormalities remains unclear. Currently, many practitioners use the presence of regression as a rationale for obtaining an EEG, to rule out a specific type of epilepsy, Landau Kleffner Syndrome (LKS) (see later). However, the literature contains incomplete and conflicting results that do not necessarily support this practice. 
Table 2. Summary of studies published since 2000 examining the prevalence of epileptiform EEGs in ASD populations (total samples and special populations within sample such as those without epilepsy)

\begin{tabular}{|c|c|c|c|c|c|c|}
\hline $\begin{array}{l}\text { Sample } \\
\text { size }\end{array}$ & Age & Ascertainment & Diagnosis & Type of EEG & Epileptiform EEG Rate & Reference \\
\hline 60 & $\begin{array}{l}\text { Mean, } 3.11 \text { y; range, } \\
2-6 \text { y }\end{array}$ & Clinic based & PDD-NOS, autism & Routine & $30 \%$ without epilepsy & 36 \\
\hline 64 & $\begin{array}{l}\text { Mean, } 36 \mathrm{mo} \text {; range, } \\
\quad 18-48 \mathrm{mo}\end{array}$ & Clinic based & Autism & Sleep & $31 \%$ without epilepsy & 37 \\
\hline 46 & Mean, 7.8 y & Clinic based & Autism, PDD & Awake and sleep & $35 \%$ overall and $22 \%$ without epilepsy & 28 \\
\hline 889 & Mean, 5.3 y & Clinic based & ASD & 24-h EEG & $60.7 \%$ without epilepsy & 13 \\
\hline 56 & Range, $1-14$ y & Clinic based & $\begin{array}{c}\text { Autism }(n=35), \text { PDD- } \\
\text { NOS }(n=18), \text { or } \\
\text { Aspergers }(n=3)\end{array}$ & Awake and sleep & $\begin{array}{c}30 \% \text { overall and } 3.6 \% \text { without epilepsy; } \\
\text { autism group, } 5.7 \% \text { without epilepsy }\end{array}$ & 38 \\
\hline 104 & Range, 30 mo- 8 y & Clinic based & Autism or ASD & Awake and sleep & $40.5 \%$ overall & 33 \\
\hline 60 & $\begin{array}{l}\text { Mean, } 17.6 \mathrm{y} \text {; range, } \\
12-29.9 \mathrm{y}\end{array}$ & Clinic Based & Autism & Awake and sleep & $6.7 \%$ without epilepsy & 30 \\
\hline 130 & Range, $18-35$ y & Clinic based & Autism and atypical & Routine & $21 \%$ without epilepsy & 11 \\
\hline 77 & Mean, 9.1 y & Clinic based & $\begin{array}{l}\text { PDD, autism, atypical } \\
\text { autism, CDD, Aspergers }\end{array}$ & Awake and sleep & $38 \%$ overall and $30 \%$ without epilepsy & 21 \\
\hline 59 & Range, $0.5-21$ y & Clinic based & Autism & Awake and sleep & $75 \%$ overall & 6 \\
\hline 32 & Mean, 5 y & Clinic based & Autism & Prolonged video-EEG & $59 \%$ without epilepsy & 14 \\
\hline 77 & Mean, 17.08 y & Clinic based & PDD-NOS and autism & Awake and sleep & $\begin{array}{l}45.5 \% \text { autism overall, } 62.3 \% \text { PDD overall, } \\
\text { and } 17.4 \% \text { PDD without epilepsy }\end{array}$ & 12 \\
\hline
\end{tabular}

Studies which include only groups ascertained for regression have reported high rates of epileptiform EEGs, from 33 to $68 \%(39,40)$. However, as a nonregression group was not included for comparison, it is not known whether there is something special about regression per se. Additionally, many studies do not separate the sample by those with and without epilepsy and so the influence of regression on epileptiform discharges in the nonepileptic sample cannot be determined.

In samples combining those with and without epilepsy, no significant association has been reported between regression and the presence of epileptiform EEGs $(29,31,33)$. Similarly, even studies limited to children without epilepsy report no significant effect of regression on epileptiform EEGs $(13,20)$. In contrast, at least two studies have found a 2-fold increase in epileptiform EEGs in those with regression (compared with and without) $(31,37)$ in patients without epilepsy.

IQ. While it is known that lower IQ influences epilepsy rates, the effect of intellectual disability on the rate of isolated epileptiform EEGs is less well studied, and the existing data are conflicting. One study found no IQ differences between those with and without epileptiform EEGs (37), but another (31) reported that epileptiform EEG was significantly more common among individuals with intellectual impairment.

Type of EEG. It seems that the rates of epileptiform discharges are influenced by the types of EEGs performed, with the highest rates in studies using overnight recordings $(13,14)$ or EEGs that include at least some sleep state recording (37). One study (13) reported the epileptiform activity was exhibited only in sleep states. Another study evaluated both types of EEG in the same patients and found that prolonged sleep EEG's significantly increased the yield of EEG abnormalities (21).

\section{Patterns of EEG Abnormalities}

If these abnormalities are taken as evidence of cortical dysfunction in autism, then examination of their types or patterns could shed light on the type of brain dysfunction.
Epileptiform EEGs seem to be more common than nonepileptiform abnormalities $(14,21,36,38,41)$. However, there seems to be no consistent pattern of epileptiform discharges across investigations with most studies reporting a variety. These include diffuse or generalized, multi-focal, and focal discharges, unilateral or bilateral and localized to many different brain areas $(6,11,13,28,30,38)$. Some studies suggest that temporal abnormalities may be more common $(13,37)$, but others do not support this view (14). The frequency of discharges is also variable $(6,33)$. Interestingly, it is rare to see the EEG pattern of electrical status epilepticus in sleep (ESES) associated with LKS (see below) in individuals with autism $(12,37)$.

Summary. The current literature would suggest that a substantial proportion of individuals with autism have epileptiform discharges in the absence of epilepsy. Yet, no clear picture emerges regarding risk factors. Nor do we have a consistent pattern of what these abnormalities might look like or what they mean. It is tempting to posit that these discharges are somehow causally related to the deficits (behavioral, communicative and cognitive) exhibited in ASD but there are very few data to support this idea.

\section{RATES OF EPILEPSY AND EEG ABNORMALITIES IN RELATED DISORDERS}

The idea that epilepsy is somehow pathophysiologically related to ASD is supported by high epilepsy rates in related disorders. Epilepsy rates in Rett syndrome range from 63 to $94 \%(42,43)$, and rates of up to $77 \%$ are seen in Childhood Disintegrative Disorder (CDD) (44). Rates in PDD-NOS are similar to those in autism (12) or perhaps somewhat lower (38). There is also a higher percentage of epilepsy and epileptiform EEGs in children with Developmental Language Disorder (DLD) $(9,45,46)$. Likewise, there is some evidence of overlapping cognitive, language and behavioral deficits in ASDs and other epilepsy syndromes supporting the possibility of a pathophysiological relationship. 
Landau-Kleffner syndrome. There has been much interest in the possible connection between autism and LKS. LKS is characterized by the rapid onset of an inability to understand spoken language in a typically developing child, usually accompanied by seizures (47). It is often associated with a severe EEG abnormality in deep sleep (electrical status epilepticus in sleep or ESES). LKS has been treated with traditional anticonvulsant medications, corticosteroids, i.v. immunoglobulins, and even epilepsy surgery (48). In many instances, both the seizures and language impairment improve with normalization of EEG abnormalities. However, the relationship between language deficits and seizures/EEG abnormalities is not completely clear. Seizures often occur only after the period of regression or not at all (15) and EEG findings do not always correlate with the severity and course of language impairment (49).

There is debate in the literature regarding whether the language regression and the accompanying EEG abnormalities in LKS can be likened to those seen in the subset of children with autistic regression and epilepsy $(31,48,50)$. The term LKS or LKS variant is now used in clinical practice for individuals with autistic regression and epileptiform EEGs. Although caution is urged because of differences in the syndromes $(48,50)$, similar treatments are sometimes used (see treatment section).

Tuberous sclerosis. TSC is a rare neurogenetic condition characterized by abnormalities in multiple systems. CNS manifestations include structural brain lesions, frequent intellectual disability, and a high prevalence of epilepsy. Although TSC is relatively uncommon (1 to 3\%) in large unselected samples of individuals with ASD (51), it is more common among individuals with both autism and epilepsy (52). Autistic symptoms are frequent in children with TSC, and ASD has been reported in up to $60 \%$ of clinic samples $(51,53)$. The reason for development of ASD in TSC remains unknown, although early onset epilepsy and the presence of intellectual disability seem to be risk factors (52). It is hypothesized that electrophysiological dysfunction in the temporal lobe disrupts the development of social communication skills (54).

Infantile spasms. Infantile spasms (IS) are a devastating early onset epilepsy syndrome with an associated severely abnormal background EEG pattern (hypsarrhythmia) and poor developmental outcome. Spasms seem to increase the risk of developing autism (55) and a percentage of ASD individuals have a history of spasms (23). In a recent study, the presence of hypsarrhythmia and frontal lobe EEG discharges were both associated with the development of ASD in children with spasms (56). However, data suggest that it might be the cause underlying the spasms rather than the spasms responsible for the increased ASD risk (57).

Benign Childhood Epilepsy syndromes. Considered "benign" because of easy to control seizures and absence of cognitive or neurologic impairment, Benign Epilepsy with Cento-Temporal Spikes (BECTS) (a.k.a Rolandic epilepsy) and Absence Epilepsy, are of interest because of emerging data suggesting subtle behavioral and cognitive problems in these patients. In BECTS, these include behavioral problems, learning disabilities, ADHD, mild cognitive and co- ordination deficits, and even specific language impairments (58). In absence epilepsy, these include subtle cognitive and linguistic deficits and a high rate of psychiatric diagnoses (59). Thus, the presence of epilepsy and epileptiform EEGs seem to predispose individuals to cognitive, linguistic, and behavioral deficits.

Some of these associations between epilepsy syndromes (infantile spasms and LKS) and ASD raise a question about whether epilepsy and/or epileptiform EEGs may play any causal role in the development of autistic behaviors. One could posit that epilepsy could alter brain development with a resulting ASD phenotype. Alternatively, abnormalities in the underlying brain substrate might cause both the epilepsy and ASD. Unfortunately, there are presently no data to answer this question.

\section{TREATMENT CONSIDERATIONS}

\section{Epilepsy}

Treatment of children with autism and epilepsy is guided by the principles of treating childhood epilepsy. Antiepileptic drugs (AEDs) are chosen based on seizure type and clinicians strive for maximum seizure control with minimum side effects. The practicalities of certain treatment choices are very important in ASD. Factors such as available formulations (liquid vs. tablets vs. capsules), dosing schedules, need for blood monitoring, and, most importantly, behavioral side effects must be considered. It is important to note that treating epilepsy does not usually have a major impact on the autism symptomatology. Some children may show improvements in cognition, communication, or behavior, but the autism diagnosis does not change.

\section{EEG Discharges}

Reports of high rates of interictal discharges are beginning to have an impact on clinical practices in autism. Although EEGs are considered standard for all children with clinical or suspected seizures, whether an EEG should be performed in all children with autism is questionable, and whether to treat these discharges if they are discovered is controversial. The concept of "treating the EEG" is based on the hypothesis that discharges may have some causal relationship to the behavioral, language, or cognitive disturbance. In general, neurologists do not treat EEGs except in very specific cases (e.g. LKS, infantile spasms). Indeed, in clinical practice it is often considered "heretical" to contemplate this (see (54) author reply). However, this may be changing.

It has long been known that interictal discharges can interfere with normal neural processing $(60,61)$. Recently, there has been more attention to the concept of deleterious transient cognitive impairment (TCI) due to the presence of background epileptiform discharges in patients with epilepsy $(62,63)$. Furthermore, there is an emerging focus on the frequent cognitive and behavioral disturbances in many childhood epilepsy syndromes (64). In BECTS, studies have shown that academic problems were related to the frequency of interictal epileptiform discharges (65) and that attentional problems largely remitted after normalization of EEG (66). Thus, one could 
posit that treatment of EEG abnormalities would have a positive impact on symptomatology in children with ASD and epileptiform EEGs.

There are a few favorable case reports of EEG treatment in autism and other childhood epilepsy syndromes $(60,67,68)$. Multiple case studies have demonstrated specific improvements in ASD symptoms after therapy to suppress discharges either with AEDs (69-71) or corticosteroids (72). It has even been suggested that the treatment of EEG discharges may prevent subsequent development of epilepsy (13). However, in the absence of results from controlled trials, the practice of medication use remains controversial.

Even more controversial is the use of epilepsy surgery (akin to those used in focal epilepsy and LKS). Several reports describe surgical treatment in individuals with autistic regression and intractable epilepsy. The degree of behavioral improvement was variable $(73,74)$ and not always related to clinical seizure control (75). Despite this, one study even extended the use of surgery to patients with epileptiform EEGs but without known seizures (40) and reported some of the patients had reduction of autistic features and improvements in language.

Unfortunately, all of these reports suffer the shortcomings of case studies, lacking controls, and reliable or standardized outcome measures. Fortunately, several recent studies investigating the treatment of interictal EEG abnormalities with AEDs use better methodology. One open label study using leviteracitam (an AED known to suppress interictal discharges) demonstrated remission of measurable auditory processing deficits in four of six children with BECTS (76). Both valproic acid and lamotrigine were shown in controlled trials to reduce interictal discharge burden and improve behavior in children with epilepsy $(77,78)$. However, it was noted that medication also reduced clinical seizure frequency, leaving open the possibility that better seizure control was responsible for the behavioral changes. A subsequent blinded placebocontrolled study of lamotrigine in children with wellcontrolled epilepsy (79) spoke to this issue, finding behavioral improvement only in the children on active drug who had a significant reduction in either frequency or duration of their interictal discharges. This study suggests that the behavioral improvement from lamotrigine was the result of the discharge suppression, not seizure control or mood stabilization. However, not all results have been positive. A cross-over placebocontrolled trial using valproic acid in patients with epileptiform EEGs showed no improvement on any behavioral measure (80) and reported some cognitive and behavioral worsening in the drug phase, leading to a cessation of the trial.

At present, there are no controlled data investigating the efficacy of treating epileptiform EEG discharges in autism, but there is increasing interest in community practices. This void creates difficulties for both practitioners and families and makes controlled investigations of this phenomenon crucial. We propose that existing results are indeed intriguing and justify further exploration of the role of these discharges in the ASD population.

\section{GENETICS}

The search for genetic determination of this comorbidity has stirred interest in a variety of genes implicated in both epilepsy and autism. For example GABA receptor genes are among the candidate autism susceptibility genes (81). Polymorphisms in sodium channel genes (82) and mutations in genes involved in synapse formation (neuroligins, neurexins, SHANK-3) (81) have been detected in some ASD families. Recently, converging evidence points to a role for CNTNAP2 (83-85) originally discovered in a family with epilepsy, cortical dysplasia, and an autism-like phenotype (86). Mutations in genes associated Rett Syndrome and its variants also predispose to epilepsy (87-91). Full discussion is beyond the scope of this review, but attention should be paid to this exciting new area that could help define pathophysiological mechanisms in both autism and epilepsy.

\section{CONCLUSION}

Despite the long recognized association between autism and epilepsy, surprisingly little is understood about the role epilepsy plays in ASD. Data from the literature suggest that lower IQ, age, gender, and comorbid medical conditions all increase epilepsy risk in the ASD population. However, in idiopathic autism samples without intellectual disability, epilepsy rates are still higher than the general population risk, suggesting that the underlying pathophysiology in ASD also increases the risk of epilepsy. Even less well studied, is the high rate of epileptiform EEGs in ASD without epilepsy. This is important to highlight because of treatment implications. If there is some causal relationship between the discharges and the ASD phenotype, and a substantial percentage of patients have epileptiform abnormalities, then there are a large number of individuals with ASD who could conceivably benefit from treatment. On the other hand, epileptiform abnormalities could be simply an epiphenomenon of the neuropathological process responsible for autism and have no relevance to prognosis or intervention.

Most recent reviews of this topic conclude with a statement about the lack of "convincing evidence" in the literature regarding the exact nature of the association between autism and epilepsy, especially regarding treatment options $(48,50)$. We believe that it is past time that we get some and would propose the following key elements in creating a research agenda.

- Large population based studies to determine the true risk of epilepsy in individuals with ASD-including detailed medical, genetic, and behavioral phenotyping to allow for determination of risk factors and prognosis.

- Studies of large cohorts of unselected samples with prolonged EEGs and detailed phenotypic data to determine the frequency and character of abnormalities and to investigate associations between types of epilepsy and EEG abnormalities and elements of the ASD phenotype (does the autism look the same?).

- Controlled intervention trials to determine whether the treatment of epileptiform EEGs has clinical utility. Positive 
results would offer a completely new treatment option for a large percentage of individuals with autism. However, negative data would allow clinicians to avoid subjecting patients to a needless (sometimes onerous) medical procedure and prevent exposure to unnecessary and potentially toxic medications or dangerous surgical interventions.

The ultimate question is one of causality: Is there a causal relationship between the EEG discharges and the ASD phenotype, and, if so, what does it mean for prognosis and intervention? Or, are the epileptiform discharges simply an epiphenomenon of the neuropathological process responsible for autism? Answers to some of these questions are crucial for formulation of much needed appropriate practice parameters both for work-up and treatment of individuals with ASD.

\section{REFERENCES}

1. Kielinen M, Rantala H, Timonen E, Linna SL, Moilanen I 2004 Associated medical disorders and disabilities in children with autistic disorder: a population-based study. Autism 8:49-60

2. Miles JH, Takahashi TN, Bagby S, Sahota PK, Vaslow DF, Wang CH, Hillman RE, Farmer JE 2005 Essential versus complex autism: definition of fundamental prognostic subtypes. Am J Med Genet A 135:171-180

3. Oliveira G, Ataide A, Marques C, Miguel TS, Coutinho AM, Mota-Vieira L, Goncalves E, Lopes NM, Rodrigues V, Carmona da Mota H, Vicente AM 2007 Epidemiology of autism spectrum disorder in Portugal: prevalence, clinical characterization, and medical conditions. Dev Med Child Neurol 49:726-733

4. Kanner L 1943 Autistic disturbances of affective contact. Nervous Child 2:217-250

5. Bryson SE, Clark BS, Smith IM 1988 First report of a Canadian epidemiological study of autistic syndromes. J Child Psychol Psychiatry 29:433-445

6. Hughes JR, Melyn M 2005 EEG and seizures in autistic children and adolescents: further findings with therapeutic implications. Clin EEG Neurosci 36:15-20

7. Clarke DF, Roberts W, Daraksan M, Dupuis A, McCabe J, Wood H, Snead OC III, Weiss SK 2005 The prevalence of autistic spectrum disorder in children surveyed in a tertiary care epilepsy clinic. Epilepsia 46:1970-1977

8. Steffenburg S, Steffenburg U, Gillberg C 2003 Autism spectrum disorders in children with active epilepsy and learning disability: comorbidity, pre- and perinatal background, and seizure characteristics. Dev Med Child Neurol 45:724-730

9. Tuchman RF, Rapin I, Shinnar S 1991 Autistic and dysphasic children. II. Epilepsy [published erratum appears in Pediatrics 1992 Aug;90(2 Pt 1):264]. Pediatrics 88:1219-1225

10. Danielsson S, Gillberg IC, Billstedt E, Gillberg C, Olsson I 2005 Epilepsy in young adults with autism: a prospective population-based follow-up study of 120 individuals diagnosed in childhood. Epilepsia 46:918-923

11. Hara H 2007 Autism and epilepsy: a retrospective follow-up study. Brain Dev 29:486-490

12. Parmeggiani A, Posar A, Antolini C, Scaduto MC, Santucci M, Giovanardi-Rossi P 2007 Epilepsy in patients with pervasive developmental disorder not otherwise specified. J Child Neurol 22:1198-1203

13. Chez MG, Chang M, Krasne V, Coughlan C, Kominsky M, Schwartz A 2006 Frequency of epileptiform EEG abnormalities in a sequential screening of autistic patients with no known clinical epilepsy from 1996to 2005. Epilepsy Behav 8:267271

14. Kim HL, Donnelly JH, Tournay AE, Book TM, Filipek P 2006 Absence of seizures despite high prevalence of epileptiform EEG abnormalities in children with autism monitored in a tertiary care center. Epilepsia 47:394-398

15. Tuchman RF 1994 Epilepsy, language, and behavior: clinical models in childhood. J Child Neurol 9:95-102

16. Fombonne E, Roge B, Claverie J, Courty S, Fremolle J 1999 Microcephaly and macrocephaly in autism. J Autism Dev Disord 29:113-119

17. Caplan R, Austin JK 2000 Behavioral aspects of epilepsy in children with mental retardation. Ment Retard Dev Disabil Res Rev 6:293-299

18. Pavone P, Incorpora G, Fiumara A, Parano E, Trifiletti RR, Ruggieri M 2004 Epilepsy is not a prominent feature of primary autism. Neuropediatrics 35:207-210

19. Volkmar FR, Nelson DS 1990 Seizure disorders in autism. J Am Acad Child Adolesc Psychiatry 29:127-129

20. Rossi PG, Parmeggiani A, Bach V, Santucci M, Visconti P 1995 EEG features and epilepsy in patients with autism [see comments]. Brain Dev 17:169-174

21. Hrdlicka M, Komarek V, Propper L, Kulisek R, Zumrova A, Faladova L, Havlovicova M, Sedlacek Z, Blatny M, Urbanek T 2004 Not EEG abnormalities but epilepsy is associated with autistic regression and mental functioning in childhood autism. Eur Child Adolesc Psychiatry 13:209-213

22. Amiet C, Gourfinkel-An I, Bouzamondo A, Tordjman S, Baulac M, Lechat P, Mottron L, Cohen D 2008 Epilepsy in autism is associated with intellectual disability and gender: evidence from a meta-analysis. Biol Psychiatry 64:577-582

23. Olsson I, Steffenburg S, Gillberg C 1988 Epilepsy in autism and autistic like conditions. A population-based study. Arch Neurol 45:666-668
24. Elia M, Musumeci SA, Ferri R, Bergonzi P 1995 Clinical and neurophysiological aspects of epilepsy in subjects with autism and mental retardation. Am J Ment Retard 100:6-16

25. Howlin P, Goode S, Hutton J, Rutter M 2004 Adult outcome for children with autism. J Child Psychol Psychiatry 45:212-229

26. Battaglia A 2005 The inv $\operatorname{dup}(15)$ or idic(15) syndrome: a clinically recognisable neurogenetic disorder. Brain Dev 27:365-369

27. Tuchman R 2003 Autism. Neurol Clin 21:915-932

28. Canitano R, Luchetti A, Zappella M 2005 Epilepsy, electroencephalographic abnormalities, and regression in children with autism. J Child Neurol 20:27-31

29. Kawasaki Y, Yokota K, Shinomiya M, Shimizu Y, Niwa S 1997 Brief report: electroencephalographic paroxysmal activities in the frontal area emerged in middle childhood and during adolescence in a follow-up study of autism. J Autism Dev Disord 27:605-620

30. Giovanardi Rossi P, Posar A, Parmeggiani A 2000 Epilepsy in adolescents and young adults with autistic disorder. Brain Dev 22:102-106

31. Tuchman RF, Rapin I 1997 Regression in pervasive developmental disorders: seizures and epileptiform electroencephalogram correlates. Pediatrics 99:560-566

32. Kobayashi R, Murata T 1998 Setback phenomenon in autism and long-term prognosis. Acta Psychiatr Scand 98:296-303

33. Giannotti F, Cortesi F, Cerquiglini A, Miraglia D, Vagnoni C, Sebastiani T, Bernabei P 2008 An Investigation of sleep characteristics, EEG abnormalities and epilepsy in developmentally regressed and non-regressed children with autism. J Autism Dev Disord 38:1888-1897

34. Capdevila OS, Dayyat E, Kheirandish-Gozal L, Gozal D 2008 Prevalence of epileptiform activity in healthy children during sleep. Sleep Med 9:303-309

35. Cavazzuti GB, Cappella L, Nalin A 1980 Longitudinal study of epileptiform EEG patterns in normal children. Epilepsia 21:43-55

36. Akshoomoff N, Farid N, Courchesne E, Haas R 2007 Abnormalities on the neurological examination and EEG in young children with pervasive developmental disorders. J Autism Dev Disord 37:887-893

37. Baird G, Robinson RO, Boyd S, Charman T 2006 Sleep electroencephalograms in young children with autism with and without regression. Dev Med Child Neurol 48:604-608

38. Gabis L, Pomeroy J, Andriola MR 2005 Autism and epilepsy: cause, consequence, comorbidity, or coincidence? Epilepsy Behav 7:652-656

39. Shinnar S, Rapin I, Arnold S, Tuchman RF, Shulman L, Ballaban-Gil K, Maw M, Deuel RK, Volkmar FR 2001 Language regression in childhood. Pediatr Neurol 24:183-189

40. Lewine JD, Andrews R, Chez M, Patil AA, Devinsky O, Smith M, Kanner A, Davis JT, Funke M, Jones G, Chong B, Provencal S, Weisend M, Lee RR, Orrison WW Jr 1999 Magnetoencephalographic patterns of epileptiform activity in children with regressive autism spectrum disorders. Pediatrics 104:405-418

41. McVicar KA, Ballaban-Gil K, Rapin I, Moshe SL, Shinnar S 2005 Epileptiform EEG abnormalities in children with language regression. Neurology 65:129-131

42. Steffenburg U, Hagberg G, Hagberg B 2001 Epilepsy in a representative series of Rett syndrome. Acta Paediatr 90:34-39

43. Cass H, Reilly S, Owen L, Wisbeach A, Weekes L, Slonims V, Wigram T, Charman T 2003 Findings from a multidisciplinary clinical case series of females with Rett syndrome. Dev Med Child Neurol 45:325-337

44. Mouridsen SE, Rich B, Isager T 1999 Epilepsy in disintegrative psychosis and infantile autism: a long-term validation study. Dev Med Child Neurol 41:110-114

45. Allen DA, Rapin I 1980 Language disorders in preschool children: predictors of outcome-a preliminary report. Brain Dev 2:73-80

46. Picard A, Cheliout Heraut F, Bouskraoui M, Lemoine M, Lacert P, Delattre J 1998 Sleep EEG and developmental dysphasia. Dev Med Child Neurol 40:595-599

47. Landau WM, Kleffner F 1957 Syndrome of acquired aphasia with convulsive disorder in children. Neurology 7:523-530

48. Tuchman R 2000 Treatment of seizure disorders and EEG abnormalities in children with autism spectrum disorders. J Autism Dev Disord 30:485-489

49. White H, Sreenivasan U 1987 Epilepsy-aphasia syndrome in children: an unusual presentation to psychiatry. Can J Psychiatry 32:599-601

50. Kanner AM 2000 Commentary: the treatment of seizure disorders and EEG abnormalities in children with autistic spectrum disorders: are we getting ahead of ourselves? J Autism Dev Disord 30:491-495

51. Wiznitzer M 2004 Autism and tuberous sclerosis. J Child Neurol 19:675-679

52. Smalley SL 1998 Autism and tuberous sclerosis. J Autism Dev Disord 28:407-414

53. Curatolo P, Porfirio MC, Manzi B, Seri S 2004 Autism in tuberous sclerosis. Eur J Paediatr Neurol 8:327-332

54. Holmes GL, Stafstrom CE 2007 Tuberous sclerosis complex and epilepsy: recent developments and future challenges. Epilepsia 48:617-630

55. Riikonen R, Amnell G 1981 Psychiatric disorders in children with earlier infantile spasms. Dev Med Child Neurol 23:747-760

56. Kayaalp L, Dervent A, Saltik S, Uluduz D, Kayaalp IV, Demirbilek V, Ghaziuddin M 2007 EEG abnormalities in West syndrome: correlation with the emergence of autistic features. Brain Dev 29:336-345

57. Saemundsen E, Ludvigsson P, Rafnsson V 2008 Risk of autism spectrum disorders after infantile spasms: a population-based study nested in a cohort with seizures in the first year of life. Epilepsia (in press)

58. Galanopoulou AS, Vidaurre J, McVicar K, Ballaban-Gil K, Shinnar S, Tuchman R, Moshe SL 2002 Language and behavioral disturbances associated with epileptiform EEGs. Am J END Technol 42:181-209

59. Caplan R, Siddarth P, Stahl L, Lanphier E, Vona P, Gurbani S, Koh S, Sankar R, Shields WD 2008 Childhood absence epilepsy: behavioral, cognitive, and linguistic comorbidities. Epilepsia (in press) 
60. Aarts JH, Binnie CD, Smit AM, Wilkins AJ 1984 Selective cognitive impairment during focal and generalized epileptiform EEG activity. Brain 107:293-308

61. Shewmon DA, Erwin RJ 1988 The effect of focal interictal spikes on perception and reaction time. I. General considerations. Electroencephalogr Clin Neurophysiol 69:319-337

62. Binnie CD 2003 Cognitive impairment during epileptiform discharges: is it ever justifiable to treat the EEG? Lancet Neurol 2:725-730

63. Holmes GL, Lenck-Santini PP 2006 Role of interictal epileptiform abnormalities in cognitive impairment. Epilepsy Behav 8:504-515

64. Besag FM 2004 Behavioral aspects of pediatric epilepsy syndromes. Epilepsy Behav 5:S3-S13

65. Piccinelli P, Borgatti R, Aldini A, Bindelli D, Ferri M, Perna S, Pitillo G, Termine C, Zambonin F, Balottin U 2008 Academic performance in children with rolandic epilepsy. Dev Med Child Neurol 50:353-356

66. Kavros PM, Clarke T, Strug LJ, Halperin JM, Dorta NJ, Pal DK 2008 Attention impairment in rolandic epilepsy: systematic review. Epilepsia 49:1570-1580

67. Gordon K, Bawden H, Camfield P, Mann S, Orlik P 1996 Valproic acid treatment of learning disorder and severely epileptiform EEG without clinical seizures. J Child Neurol 11:41-43

68. Rugland AL 1990 Neuropsychological assessment of cognitive functioning in children with epilepsy. Epilepsia 31:S41-S44

69. Hollander E, Dolgoff-Kaspar R, Cartwright C, Rawitt R, Novotny S 2001 An open trial of divalproex sodium in autism spectrum disorders. J Clin Psychiatry 62:530534

70. Nass R, Petrucha D 1990 Acquired aphasia with convulsive disorder: a pervasive developmental disorder variant. J Child Neurol 5:327-328

71. Plioplys AV 1994 Autism: electroencephalogram abnormalities and clinical improvement with valproic acid. Arch Pediatr Adolesc Med 148:220-222

72. Stefanatos GA, Grover W, Geller E 1995 Case study: corticosteroid treatment of language regression in pervasive developmental disorder. J Am Acad Child Adolesc Psychiatry 34:1107-1111

73. Nass R, Gross A, Wisoff J, Devinsky O 1999 Outcome of multiple subpial transections for autistic epileptiform regression. Pediatr Neurol 21:464-470

74. Neville BG, Harkness WF, Cross JH, Cass HC, Burch VC, Lees JA, Taylor DC 1997 Surgical treatment of severe autistic regression in childhood epilepsy. Pediatr Neurol $16: 137-140$

75. Szabo CA, Wyllie E, Dolske M, Stanford LD, Kotagal P, Comair YG 1999 Epilepsy surgery in children with pervasive developmental disorder. Pediatr Neurol 20:349353

76. Kossoff EH, Los JG, Boatman DF 2007 A pilot study transitioning children onto levetiracetam monotherapy to improve language dysfunction associated with benign rolandic epilepsy. Epilepsy Behav 11:514-517

77. Eriksson AS, Knutsson E, Nergardh A 2001 The effect of lamotrigine on epileptiform discharges in young patients with drug-resistant epilepsy. Epilepsia 42:230236

78. Marston D, Besag F, Binnie CD, Fowler M 1993 Effects of transitory cognitive impairment on psychosocial functioning of children with epilepsy: a therapeutic trial. Dev Med Child Neurol 35:574-581
79. Pressler RM, Robinson RO, Wilson GA, Binnie CD 2005 Treatment of interictal epileptiform discharges can improve behavior in children with behavioral problems and epilepsy. J Pediatr 146:112-117

80. Ronen GM, Richards JE, Cunningham C, Secord M, Rosenbloom D 2000 Can sodium valproate improve learning in children with epileptiform bursts but without clinical seizures? Dev Med Child Neurol 42:751-755

81. Abrahams BS, Geschwind DH 2008 Advances in autism genetics: on the threshold of a new neurobiology. Nat Rev Genet 9:341-355

82. Weiss LA, Escayg A, Kearney JA, Trudeau M, MacDonald BT, Mori M, Reichert J, Buxbaum JD, Meisler MH 2003 Sodium channels SCN1A, SCN2A and SCN3A in familial autism. Mol Psychiatry 8:186-194

83. Alarcon M, Abrahams BS, Stone JL, Duvall JA, Perederiy JV, Bomar JM, Sebat J, Wigler M, Martin CL, Ledbetter DH, Nelson SF, Cantor RM, Geschwind DH 2008 Linkage, association, and gene-expression analyses identify CNTNAP2 as an autism-susceptibility gene. Am J Hum Genet 82:150-159

84. Arking DE, Cutler DJ, Brune CW, Teslovich TM, West K, Ikeda M, Rea A, Guy M, Lin S, Cook EH, Chakravarti A 2008 A common genetic variant in the neurexin superfamily member CNTNAP2 increases familial risk of autism. Am J Hum Genet $82: 160-164$

85. Bakkaloglu B, O'Roak BJ, Louvi A, Gupta AR, Abelson JF, Morgan TM, Chawarska K, Klin A, Ercan-Sencicek AG, Stillman AA, Tanriover G, Abrahams BS, Duvall JA, Robbins EM, Geschwind DH, Biederer T, Gunel M, Lifton RP, State MW 2008 Molecular cytogenetic analysis and resequencing of contactin associated protein-like 2 in autism spectrum disorders. Am J Hum Genet 82:165-173

86. Strauss KA, Puffenberger EG, Huentelman MJ, Gottlieb S, Dobrin SE, Parod JM, Stephan DA, Morton DH 2006 Recessive symptomatic focal epilepsy and mutant contactin-associated protein-like 2. N Engl J Med 354:1370-1377

87. Jian L, Nagarajan L, de Klerk N, Ravine D, Christodoulou J, Leonard H 2007 Seizures in Rett syndrome: an overview from a one-year calendar study. Eur J Paediatr Neurol 11:310-317

88. Evans JC, Archer HL, Colley JP, Ravn K, Nielsen JB, Kerr A, Williams E, Christodoulou J, Gecz J, Jardine PE, Wright MJ, Pilz DT, Lazarou L, Cooper DN, Sampson JR, Butler R, Whatley SD, Clarke AJ 2005 Early onset seizures and Rett-like features associated with mutations in CDKL5. Eur J Hum Genet 13:11131120

89. Grosso S, Brogna A, Bazzotti S, Renieri A, Morgese G, Balestri P 2007 Seizures and electroencephalographic findings in CDKL5 mutations: case report and review. Brain Dev 29:239-242

90. Mari F, Azimonti S, Bertani I, Bolognese F, Colombo E, Caselli R, Scala E, Longo I, Grosso S, Pescucci C, Ariani F, Hayek G, Balestri P, Bergo A, Badaracco G, Zappella M, Broccoli V, Renieri A, Kilstrup-Nielsen C, Landsberger N 2005 CDKL5 belongs to the same molecular pathway of MeCP2 and it is responsible for the early-onset seizure variant of Rett syndrome. Hum Mol Genet 14:1935-1946

91. Scala E, Ariani F, Mari F, Caselli R, Pescucci C, Longo I, Meloni I, Giachino D, Bruttini M, Hayek G, Zappella M, Renieri A 2005 CDKL5/STK9 is mutated in Rett syndrome variant with infantile spasms. J Med Genet 42:103-107 